Research Article

\title{
Experimental Research on Microstructure and Physical-Mechanical Properties of Expansive Soil Stabilized with Fly Ash, Sand, and Basalt Fiber
}

\author{
Qin-yong Ma $\mathbb{D}^{1,2}$ Zi-ming Cao ${ }^{1 D},^{1,2}$ and Pu Yuan $\mathbb{D i D}^{1,2}$ \\ ${ }^{1}$ Engineering Research Center of Underground Mine Construction, Ministry of Education, \\ Anhui University of Science and Technology, Huainan, Anhui 232001, China \\ ${ }^{2}$ School of Civil Engineering and Architecture, Anhui University of Science and Technology, Huainan, Anhui 232001, China
}

Correspondence should be addressed to Zi-ming Cao; ziming_cao@foxmail.com

Received 30 May 2018; Accepted 17 September 2018; Published 21 October 2018

Academic Editor: Carlo Santulli

Copyright (C) 2018 Qin-yong Ma et al. This is an open access article distributed under the Creative Commons Attribution License, which permits unrestricted use, distribution, and reproduction in any medium, provided the original work is properly cited.

Expansive soil is a source of risk to the foundations or subgrade engineering. Stabilization of expansive soil is imperative for practical engineering. A series of laboratory experiments were performed to analyze the physical-mechanical properties and microstructures of stabilized soil. Three stabilizers used in this study are fly ash, sand, and basalt fiber. Different percentages of fly ash $(0,5,10,15$, and 20\%), sand $(0,8,16$, and 24\%), and basalt fiber ( 0 and $0.4 \%)$ were added by weight into natural soil. Experimental results indicate that the optimum moisture content of stabilized soil increases with the increase of fly ash content for a given sand content, whereas the maximum dry density shows a decreasing trend. The variation trend of optimum moisture content and maximum dry density turns reverse with the increase of sand content for a given fly ash content. Plasticity index is decreased by both increasing fly ash content and sand content. It is found that the maximum unconfined compressive strength and optimum growth rate of strength are obtained by selected mixtures of $10 \%$ fly ash, $8 \%$ sand, and $0.4 \%$ basalt fiber contents. As the analysis of complementary effect suggests, most of the mixt treatments applied in this study have produced good results associated with the strength enhancement of expansive soil. In line with the results of SEM tests, the connection among clay particles has been enhanced through the generation of hydration products (C-S-H and AFt) of fly ash. The filling effect of sand has increased the integrality and compactness of stabilized soil. Moreover, the gripping effect between fibers and soil particles notably improves the strength of stabilized soil. The effect of sand on reinforced soil with $0.4 \%$ basalt fiber increases the interfacial force between fibers and soil particles.

\section{Introduction}

Expansive soil is a kind of high-plasticity clay with strong hydrophilic mineral components, such as montmorillonite and illite. It presents the swelling property when absorbing water and shrinking property when losing water $[1,2]$. Due to the unstable behavior of expansive soil, it is easy to cause a series of engineering disasters, inclusive of differential settlement of subgrade, incline and subsidence of buildings, and collapse of slope occurrence. Besides, the particular features of expansive soil will bring severe safety hazards and economic losses to expansive soil areas. Given these situations, improving the physical and mechanical properties of expansive soil is indispensable for stability of foundation and subgrade engineering.

In recent decades, how to find a feasible and economical method to improve engineering properties of expansive soil has posed a huge challenge to geotechnical engineers. In the meantime, some researchers have investigated various methods for expansive soil stabilization. The effect of lime, cement, and fly ash on the physical-mechanical behaviors of soil samples is also confirmed by the research of modified methods on expansive soils. As the test results of Yong and Ouhadi [3] suggested, lime or cement stabilization is practical to abate the deterioration of bearing capacity of expansive soil. As Khemissa and Mahamedi [4] reported, the 
cement-lime mixture amendment has improved the strength and durability of expansive clay remarkably. Furthermore, the effect of cement and lime on the plasticity, swelling behaviors, and strength properties of expansive soils is also confirmed by Al-Mukhtar et al. [5], Estabragh et al. [6], Sharma et al. [7], and Thyagaraj et al. [8] in their studies of improvement on expansive soils. Phanikumar and Sharma [9], Rao and Rao [10], and Feng et al. [11] found that fly ash is a suitable stabilizer to reduce the swelling property of expansive soil and improve its mechanical performance. Accordingly, chemical stabilization has been considered a practical and effective solution to reduce swell-shrink characteristics and improve physical-mechanical properties of expansive soil. From the perspective of economy and environmental protection, the industrial wastes, such as fly ash, must be treated in an appropriate way. Fly ash can be added scientifically in expansive soils to modify their plasticity index, free swelling ratio, and mechanical properties [12]. When fly ash is added into expansive soils, the reaction with clay particles will improve the strength, consolidation, and drainage characteristics [13]. In aspect of physical stabilization, sand is a nonexpansive soil with minimum plasticity and has no type of charge on its surface. The addition of sand into expansive soil helps to balance the electrical charge in expansive soil and then mitigates the expansion [14]. In addition, sand is broadly applied in civil engineering materials by its abundant source and low price. Another physical stabilization of expansive soil is fiber reinforcement. The basic principle of fiber-reinforced expansive soil is that it utilizes the frictional force between fibers and soil particles to constrain the deformation of soil, and the physical-mechanical properties of expansive soil improve significantly [15-18]. Given that basalt fiber is characterized by environmental protection, good compatibility, and superior mechanical properties $[19,20]$, it is also selected as an additive into the soil specimens during the experiment. The previous investigations primarily concentrated on the macro-characteristics of expansive soil, and limited studies are available on microstructural analysis of stabilized expansive soil. The experiment of microstructure not only reflects the internal structure changes before and after the improvement of soil specimens but also explains the intrinsic mechanism of soil stabilization [21, 22].

In the following chapters of this paper, an experimental study has been conducted for expansive soil stabilized with fly ash, sand, and basalt fiber. This paper aims to study the effect of the noted three additives on physical-mechanical and microstructural characteristics of expansive soil which can be satisfactorily applied for construction of foundations, subgrade, road, and even driveways after reasonable and effective treatments.

\section{Experimental Materials and Methods}

2.1. Experimental Materials. The test expansive soil specimens were procured from a subway construction site in Hefei, Anhui Province. Hefei is known as a typical expansive soil area. The test results of physical properties of natural soil are shown in Table 1 and Figure 1.
The fly ash was collected from the thermal power plant in Huainan, Anhui Province. The primary chemical compositions of fly ash are $\mathrm{SiO}_{2}, \mathrm{Al}_{2} \mathrm{O}_{3}, \mathrm{Fe}_{2} \mathrm{O}_{3}$, and $\mathrm{CaO}$. The percentage of $\mathrm{SiO}_{2}, \mathrm{Al}_{2} \mathrm{O}_{3}, \mathrm{Fe}_{2} \mathrm{O}_{3}$, and $\mathrm{CaO}$ is 40.12, 23.58, 6.39, and 15.65, respectively. Other chemical compositions have taken up $14.26 \%$. Based on the chemical composition of fly ash, it can be classified as class-C fly ash according to ASTM C618 Standard Specification [23].

The sand applied in this study is commercially available Xiamen sand. The fineness modulus of sand reaches 2.31 .

Basalt fiber is a material made from extremely fine fibers of basalt, encompassed by the minerals plagioclase, pyroxene, and olivine. Basalt fiber has been broadly used in scientific experiments by its excellent mechanical characteristics and green features. The major performance indices of the basalt fiber used in this study are listed in Table 2.

2.2. Specimens Preparation and Experimental Methods. In this study, the soil specimens blended with various additives were tested to determine their physical-mechanical and microstructural properties. Fly ash and sand were added into the soil samples in different percentages on dry weight basis of expansive soil. The content of fly ash falls into five grades, i.e., $0 \%, 5 \%, 10 \%, 15 \%$, and $20 \%$. Besides, the content of sand falls into four grades, i.e., $0 \%, 8 \%, 16 \%$, and $24 \%$. The basalt fibers were dispersed into soil samples at $0 \%$ and $0.4 \%$.

The physical performance index of expansive soil specimens was determined in line with the pertinent tests specified in GB/T 50123-1999 [24]. All the soil specimens of the unconfined compression test keep the same moisture content of $18.9 \%$ and the same dry density of $1.76 \mathrm{~g} / \mathrm{cm}^{3}$. The loading rate of unconfined compression test was fixed at $1 \mathrm{~mm} / \mathrm{min}$. The preparation procedures of stabilized soil specimen are as follows: (1) the dry soil samples were crushed and passed through a $2 \mathrm{~mm}$ sieve; (2) the sifted soil particles were put in a drying oven at a constant temperature of $105^{\circ} \mathrm{C}$ for more than $24 \mathrm{~h}$; (3) the dry soil, fly ash, sand, basalt fiber, and distilled water were fully mixed before the preparation of the soil specimens, and then the mixtures were put in an airtight container for $24 \mathrm{~h}$ to make soil samples moisture equilibrium; (4) the prepared mixtures were placed into a compacting mold with a height of $100 \mathrm{~mm}$ and a diameter of $50 \mathrm{~mm}$ at least five times; (5) the prepared samples were kept in a standard curing chamber at a constant temperature of $20 \pm 2{ }^{\circ} \mathrm{C}$ and $95 \%$ relative humidity for 28 days. The soil specimens were investigated through the scanning electron microscopy (SEM) method to observe the changes in the microstructure. The SEM observations were conducted on blocks taken from a cylindrical sample with a height of $100 \mathrm{~mm}$ and a diameter of $50 \mathrm{~mm}$. All the SEM samples were kept in a dryer for $24 \mathrm{~h}$ before the microstructural experiment. In addition, the SEM samples were gold coated by a sputtering technique to make them conductive after drying process. The SEM examinations were performed using a Quanta FEG 650 scanning electron microscope manufactured by FEI Corporation. 
TABLe 1: Physical properties of expansive soil.

\begin{tabular}{lcccccc}
\hline Specific gravity & $\begin{array}{c}\text { Optimum moisture } \\
\text { content }(\%)\end{array}$ & $\begin{array}{c}\text { Maximum dry } \\
\text { density }\left(\mathrm{g} / \mathrm{cm}^{3}\right)\end{array}$ & $\begin{array}{c}\text { Liquid } \\
\text { limit }(\%)\end{array}$ & $\begin{array}{c}\text { Plastic } \\
\text { limit }(\%)\end{array}$ & $\begin{array}{c}\text { Plasticity } \\
\text { index }(\%)\end{array}$ & $\begin{array}{c}\text { Free swell } \\
\text { ratio }(\%)\end{array}$ \\
\hline 2.71 & 18.9 & 1.76 & 42.8 & 22.0 & 20.8 & 46 \\
\hline
\end{tabular}

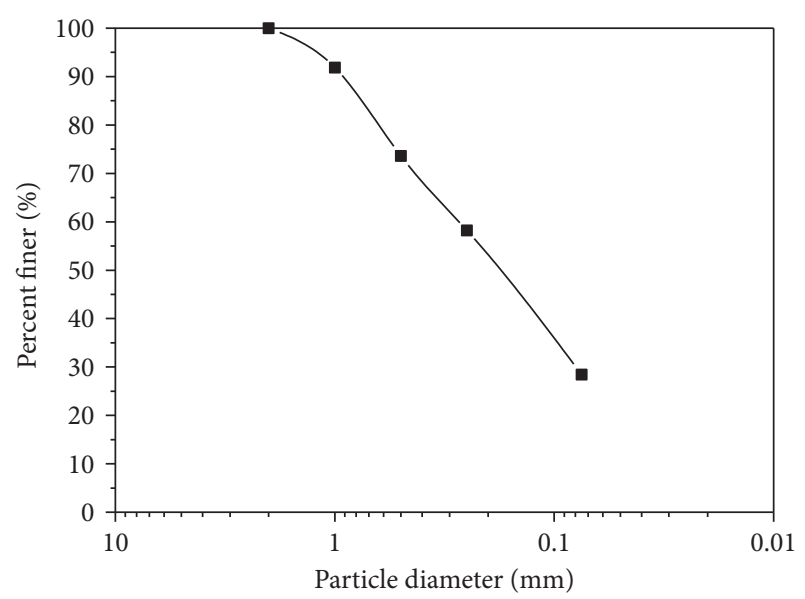

FIgURE 1: Grain-size distribution curve.

TABLE 2: Physical and mechanical properties of basalt fiber.

\begin{tabular}{lcccc}
\hline $\begin{array}{l}\text { Density } \\
\left(\mathrm{g} / \mathrm{cm}^{3}\right)\end{array}$ & $\begin{array}{c}\text { Average } \\
\text { length } \\
(\mathrm{mm})\end{array}$ & $\begin{array}{c}\text { Tensile } \\
\text { strength } \\
(\mathrm{GPa})\end{array}$ & $\begin{array}{c}\text { Elasticity } \\
\text { modulus } \\
(\mathrm{GPa})\end{array}$ & $\begin{array}{c}\text { Elongation } \\
\text { at break } \\
(\%)\end{array}$ \\
\hline 2.8 & 9 & $3.5 \sim 4.0$ & $90 \sim 110$ & 3.2 \\
\hline
\end{tabular}

\section{Physical-Mechanical Test Results and Discussions}

3.1. Specific Gravity. Specific gravity of natural expansive soil and stabilized soil samples obtained from the pycnometer is shown in Figures 2(a) and 2(b). The specific gravity value for expansive soil is 2.71. It is observed from the fitting results shown in Figure 2(a) that the specific gravity of stabilized soil samples decreases almost linearly with increasing of fly ash content. In contrast, the specific gravity of stabilized soil specimens increases almost linearly with the increase of sand content. The reason is that the virgin soil samples are heavier particles compared with fly ash and lighter particles compared with sand.

3.2. Compaction Characteristics. To study the water stability of stabilized soil, compaction tests were performed on stabilized expansive soil with different percentages of fly ash and sand. The curves of the optimum moisture content and maximum dry density can be acquired by performing the compaction tests. This compaction test adopts a light compaction test, and each group of test has prepared five soil specimens with different moisture contents. Each soil specimen was compacted in three layers and compacted 25 times per layer [24]. The results of compaction tests are shown in Figure 3. When the dosage of sand is $0 \%$, the optimum moisture content gradually increases from $18.9 \%$ to $21.6 \%$ with the increase of fly ash content, as presented in Figure 3(a). However, the value of optimum moisture content changes from $15.3 \%$ to $18.9 \%$ with the addition of $0 \%$ fly ash to the virgin soil specimens. With the constant dosage of fly ash, the value of optimum moisture content decreases with increasing percentage of sand. It is clear as shown in Figure 3(a) that the value of optimum moisture content has the fastest reduction rate with $24 \%$ sand content.

With increasing of fly ash content, Figure 3(b) presents a reducing trend of maximum dry density of stabilized soil. In contrast, the maximum dry density shows an increasing trend with the increase of sand content. When the sand content is $0 \%$, the maximum dry density gradually decreases from $1.76 \mathrm{~g} / \mathrm{cm}^{3}$ to $1.43 \mathrm{~g} / \mathrm{cm}^{3}$ with increasing of fly ash content. This is because the relative volumetric mass of fly ash is smaller than that of expansive soil. With the fly ash content of $0 \%$, the maximum dry density of stabilized soil samples increases from $1.76 \mathrm{~g} / \mathrm{cm}^{3}$ to $2.05 \mathrm{~g} / \mathrm{cm}^{3}$ as the sand content increases from $0 \%$ to $24 \%$. This is probably because the relative volumetric mass of sand is higher than that of soil particles. With the sand dosage of $24 \%$, the maximum dry density of stabilized soil has the fastest growth rate except for the soil samples with $10 \%$ fly ash and $24 \%$ sand.

3.3. Plastic Limit, Liquid Limit, and Plasticity Index. Plastic limit, liquid limit, and plasticity index of expansive soil specimens stabilized with fly ash or sand are shown in Figures 4-6, respectively.

From Figures 5 and 6, it can be seen that the liquid limit and plasticity index decrease with the increase of fly ash content. However, the plastic limit increases with the increase of fly ash content in Figure 4. Under the sand dosage of $0 \%$, the value of the plastic limit increases from $22.0 \%$ to $27.5 \%$, the value of the liquid limit decreases from $42.8 \%$ to $34.9 \%$, and the value of the plasticity index notably decreases from $20.8 \%$ to $7.4 \%$ with increasing of fly ash dosage. The nonplastic characteristics of stabilized soil improve with the increase of fly ash dosage in soil specimens. With the increase of fly ash content, the high cations $\left(\mathrm{Al}^{3+}, \mathrm{Fe}^{3+}\right.$, and $\mathrm{Ca}^{2}$ $\left.{ }^{+}\right)$of fly ash components exchange with the low cations $\left(\mathrm{K}^{+}\right.$ and $\mathrm{Na}^{+}$) on the clay particle surface [11]. There is an ion exchange interaction between fly ash and soil particles with the presence of fly ash, which improves the flocculation of clay particles $[9,11]$. Therefore, the plasticity index decreases significantly with the reduction of the amount of clay particles and hydrophilic minerals. The results obtained in this study are similar to Feng et al. [11] and Kolay and Ramesh [14]. It is found that the plasticity index is a good indicator of swelling behaviors, namely, a lower plasticity index indicates a weaker expansibility [21]. In addition, the liquid limit decreases slightly with the increase of sand content. The plastic limit generally shows an increasing 


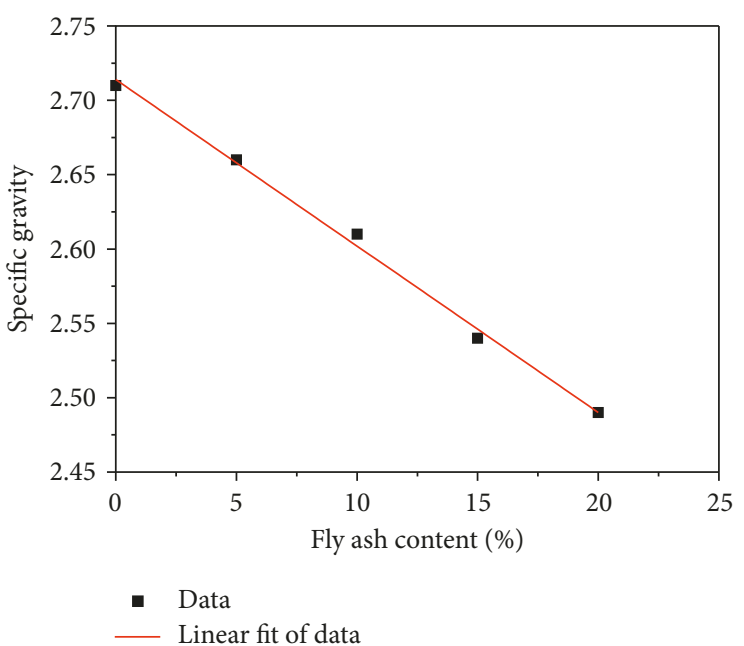

(a)

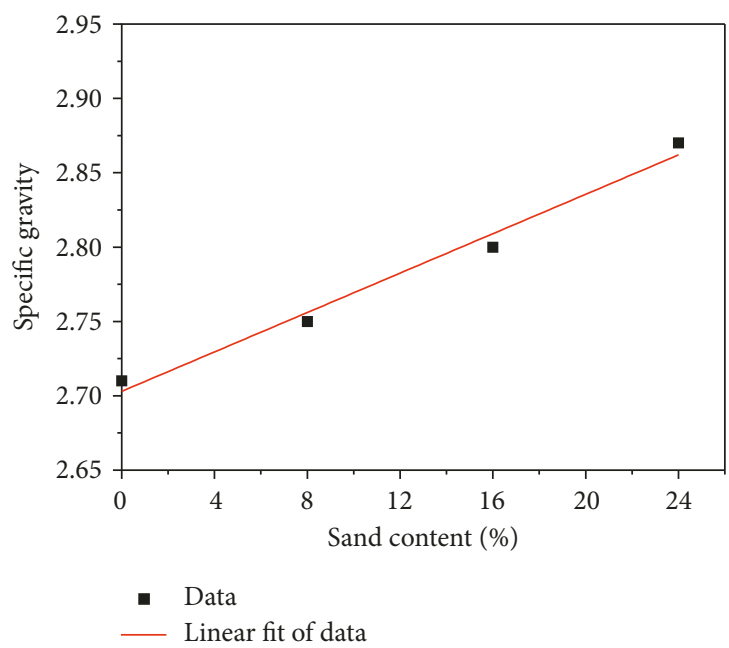

(b)

FIGURE 2: Specific gravity of stabilized expansive soil. (a) Expansive soil stabilized with fly ash. (b) Expansive soil stabilized with sand.

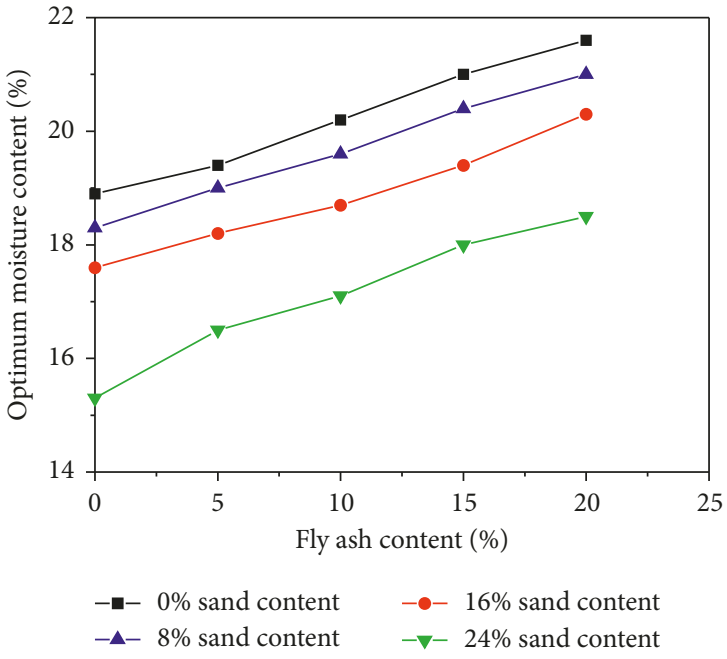

(a)

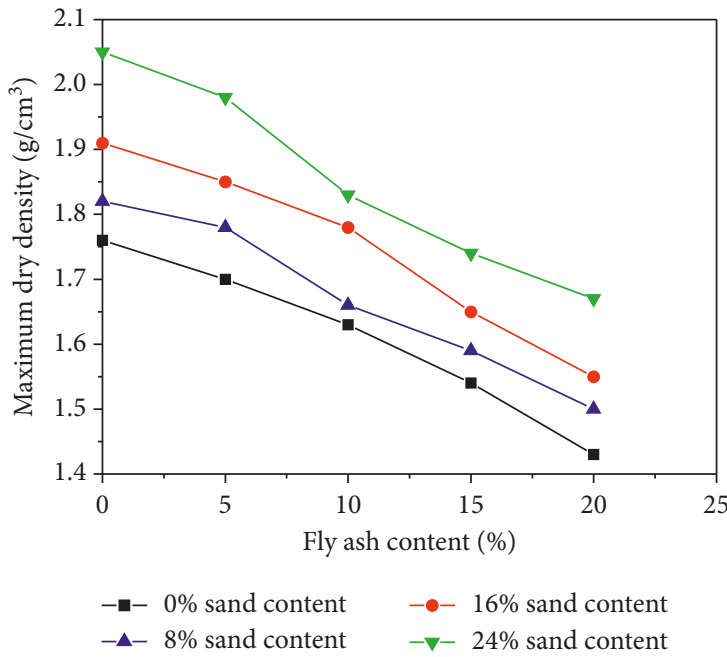

(b)

FIgURE 3: The compaction characteristics of stabilized expansive soil. (a) Optimum moisture content. (b) Maximum dry density.

trend with the increase of sand content. When the sand dosage is $24 \%$, the incremental gradient of the plastic limit value is the largest because sand is virtually noncohesive.

\subsection{Unconfined Compressive Tests}

3.4.1. Axial Stress-Strain Curves. Figures 7 and 8 present the relationships between axial stress and strain, with regard to unreinforced and fiber-reinforced soil samples with different fly ash and sand contents. All the stress-strain curves in Figures 7 and 8 show a similar variation tendency, and they fall into three stages, i.e., elastic stage, plastic stage, and failure stage. In the elastic stage, the stress increases linearly with the increase of the strain. In the plastic stage, the incremental gradient of stress slows down, yet the stress continues to increase progressively. The increase of the incremental gradient of stress is approximately zero, and no conspicuous trend of further growth is observed. In the last stage, the axial stress decreases as the axial strain increases. This stage indicates the deterioration of soil samples. The soil samples have the same conditions in Figures 7(a) and 7(b), which suggest that the dosage of sand is $0 \%$, and the fly ash contents are $0 \%, 5 \%, 10 \%, 15 \%$, and $20 \%$, respectively. The only difference is that all the soil samples in Figure $7(\mathrm{~b})$ added $0.4 \%$ basalt fiber. It can be observed that the axial stress of the stabilized soil samples increases when the fly ash content is lower than $10 \%$ and decreases when the fly ash content exceeds $10 \%$. All the values of maximum axial stress in Figure 7(b) are notably larger than that in Figure 7(a). From the beginning of the plastic stage to the end of the failure stage, all stress-strain curves in Figure 7(b) have 


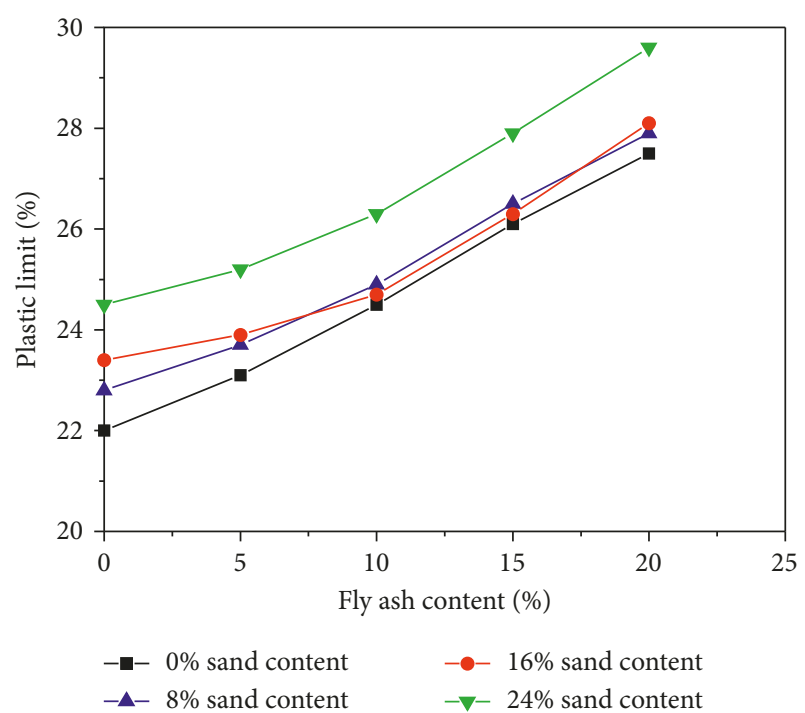

FIgURE 4: Plastic limit of stabilized expansive soil.

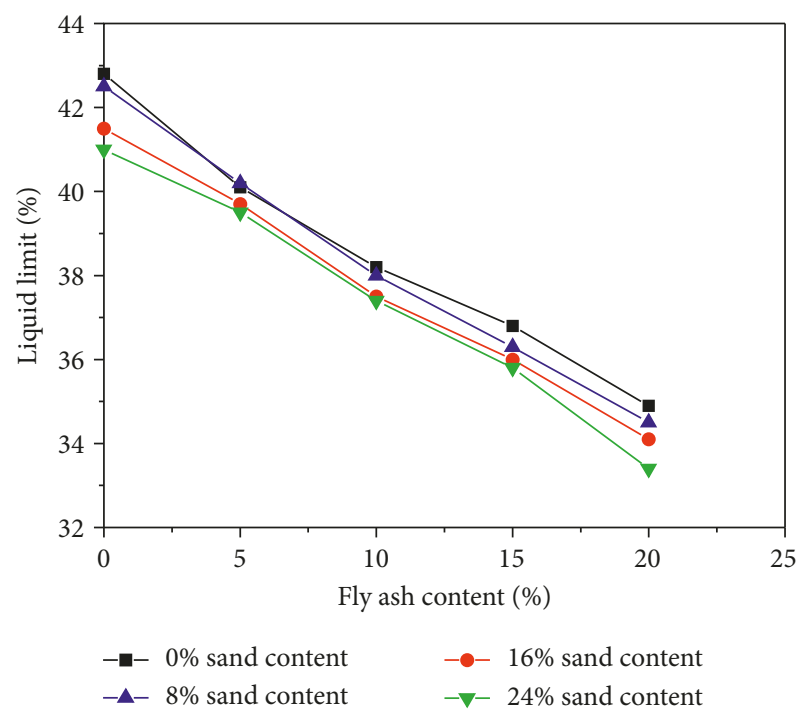

FIgURE 5: Liquid limit of stabilized expansive soil.

changed gently and maintained a relatively flat variation trend for a long time. Conversely, the stress-strain curves in Figure 7 (a) have changed rapidly. Given a reasonable interpretation, a stable three-dimensional space structure system is formed inside soil with the addition of basalt fiber, which enhances the interfacial force between fibers and soil particles [20]. With the interaction of the bonding force and frictional resistance between fibers and soil particles, the basalt fiber sustains the tensile stress caused by the further deformation of the soil samples under loading. Accordingly, fiber-reinforced soil effectively constrains the continuous development of soil deformation, which shows a significant increase in maximum axial stress as compared with the stabilized soil samples with no basalt fiber.

The effect of sand dosage on the strength enhancement can be found in Figure 8(a). The effect of sand dosage on the maximum axial stress of sand-stabilized soil shows a similar

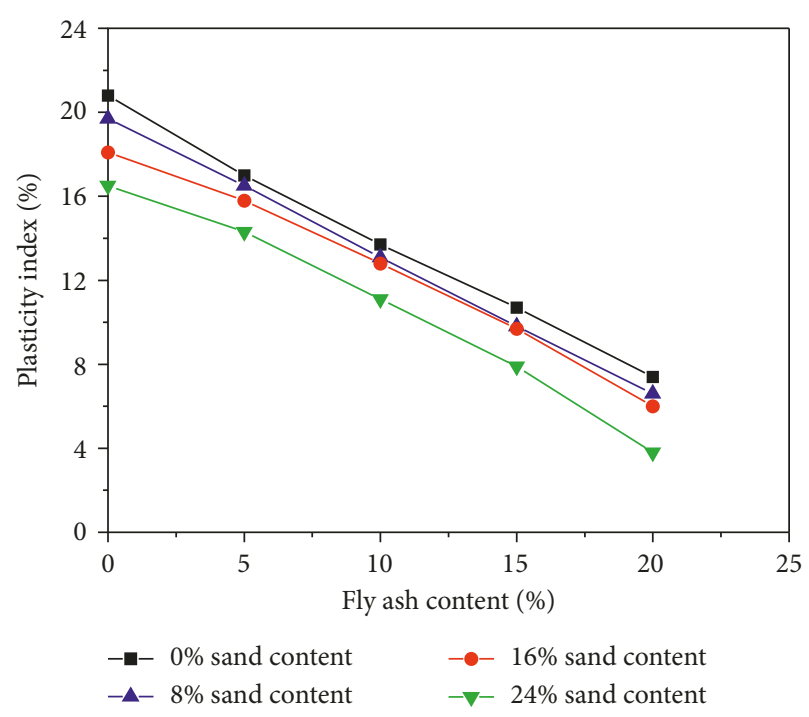

Figure 6: Plasticity index of stabilized expansive soil.

feature with the effect of fly ash dosage on maximum axial stress. It is found that the optimal content of sand for the maximum axial stress of sand-stabilized soil is $8 \%$. When the dosage of sand is rather more, the maximum axial stress of sand-stabilized soil decreases obviously. The reinforcement effect of basalt fiber on sand-stabilized soil is similar to the effect of fiber on fly ash-stabilized soil. The occurrence of maximum axial stress of fiber-sand-stabilized soil is corresponding to $8 \%$ sand content and $0.4 \%$ basalt fiber content. The maximum axial stress has a higher enhancement of fiber-sand-stabilized soil compared with sand-stabilized soil, as illustrated in Figure 8(b).

3.4.2. Unconfined Compressive Strength. Unconfined compressive strength is determined by the ultimate strength of soil that resists axial pressure under no lateral pressure. And the unconfined compressive strength is one of the important indices to reflect the mechanical properties of stabilized soil, and it often serves as a crucial basis for the design of road, subgrade, and foundation. The unconfined compression tests were performed with natural expansive soil and stabilized soil with fly ash, sand, and basalt fiber. The results of these tests are illustrated in Figure 9. The unconfined compressive strength of stabilized soil specimens increases progressively with both increasing fly ash content and sand content. The optimum contents of fly ash and sand for maximum unconfined compressive strength of stabilized soil were found to be $10 \%$ and $8 \%$, respectively. For fly ashstabilized soil, the maximum value of unconfined compressive strength suggested that with the increase of fly ash dosage, the occurrence of flocculation between fly ash particles and soil particles is improved until the fly ash dosage reaches its optimum value. When the fly ash content exceeds its optimum value, the excessive fly ash particles remaining in soil specimens are equal to the increase of silt particles in total soil particles. As a result, the strength of soil specimens decreases gradually with the addition of excessive 


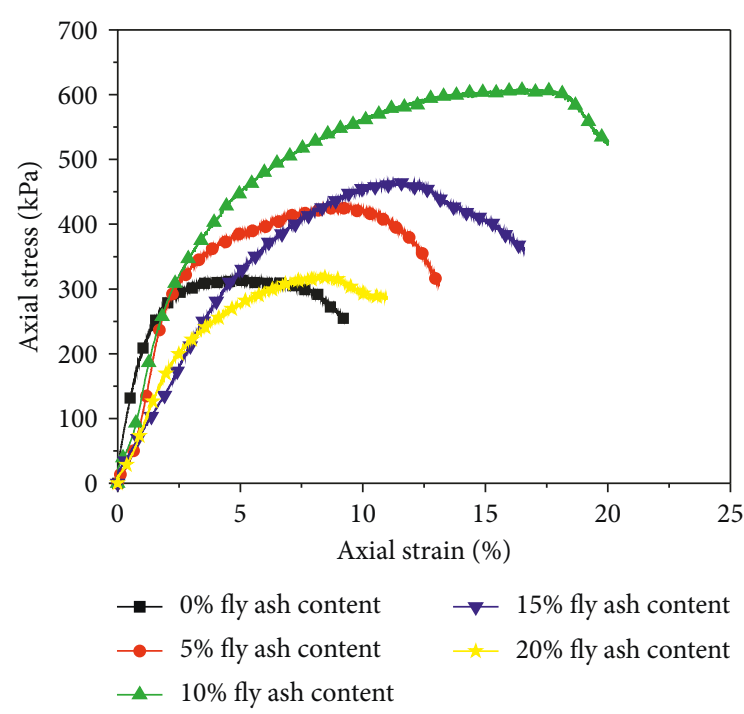

(a)

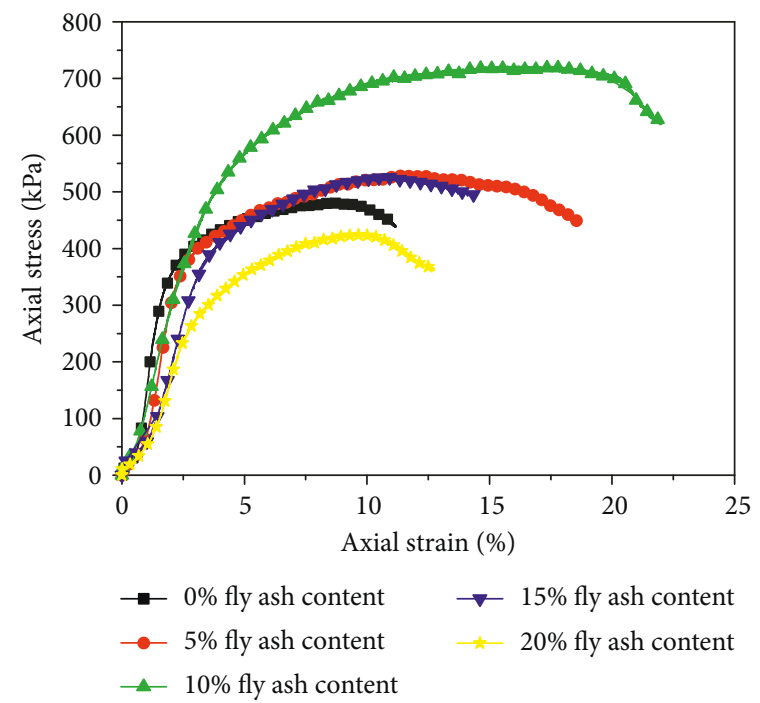

(b)

FIgURE 7: Stress-strain curves of stabilized expansive soil under different fly ash contents. (a) Without basalt fiber. (b) With $0.4 \%$ basalt fiber.

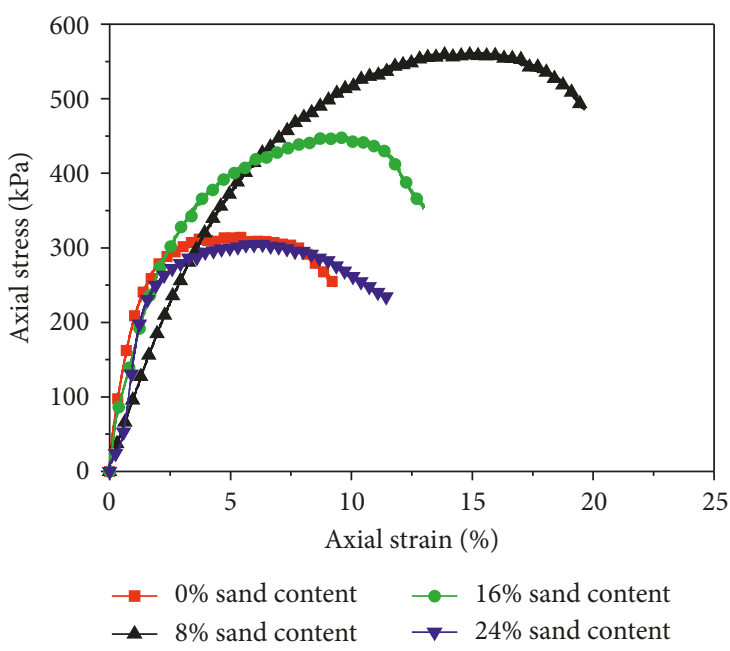

(a)

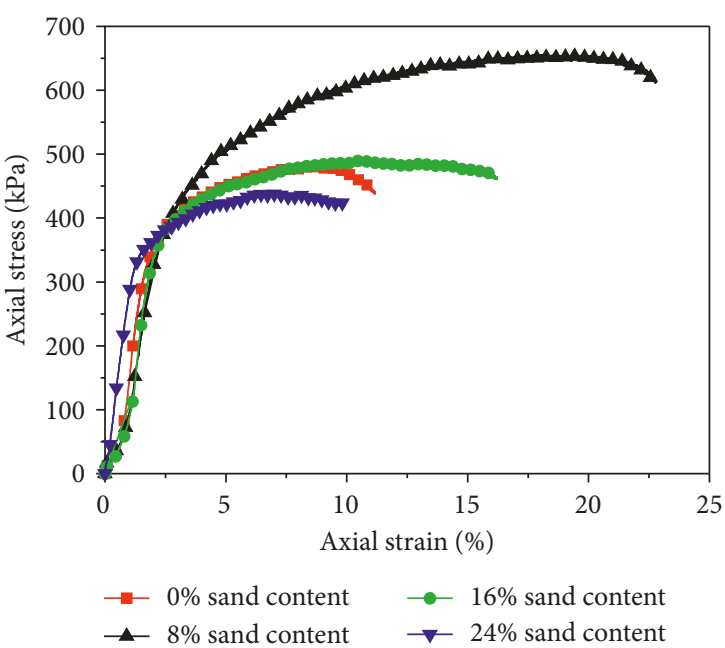

(b)

FiguRE 8: Stress-strain curves of stabilized expansive soil under different sand contents. (a) Without basalt fiber. (b) With $0.4 \%$ basalt fiber.

fly ash. Furthermore, the fly ash itself has no cohesion, which directly leads to the reduction of the strength of stabilized soil. For the soil stabilized with sand, the filling effect of sand increases the compactness and integrality of internal structure of stabilized soil, and the strength of stabilized soil also presents an evident uptrend. Moreover, the sand, considered as a hard particle, can effectively prevent the relative sliding of crack appeared inside the soil structures [25]. With the further increase of sand content, there are more sand-sand joint surfaces occurring inside the soil samples. Therefore, the unconfined compressive strength increases firstly and then decreases with the increase of sand content. As the results in Figures 9(a) and 9(b) show, the interaction between fly ash and sand enables the maximum strength of stabilized soil specimens under the optimum values for fly ash and sand content. It can be considered that the binding force among the fly ash, sand, and soil particles reaches the biggest value with the mixt addition of $10 \%$ fly ash and $8 \%$ sand into expansive soil. Besides, all the maximum strength values in Figure 9(b) are larger than those shown in Figure 9(a) because of the fiber reinforcement to stabilized soil.

The growth rate of unconfined compressive strength is an important index to measure the strength enhancement of stabilized soil. The growth rate of unconfined compressive strength can be defined by the following equation:

$$
\eta=\frac{\sigma_{x}-\sigma_{0}}{\sigma_{0}} \times 100 \%
$$

where $\sigma_{0}$ denotes the unconfined compressive strength of untreated soil samples and $\sigma_{x}$ refers to the unconfined compressive strength of stabilized soil with different additives. 


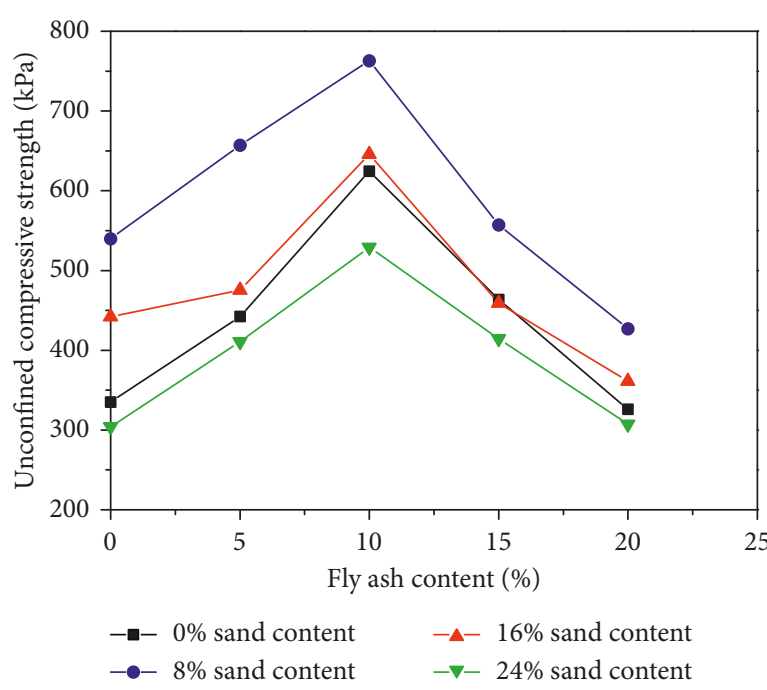

(a)

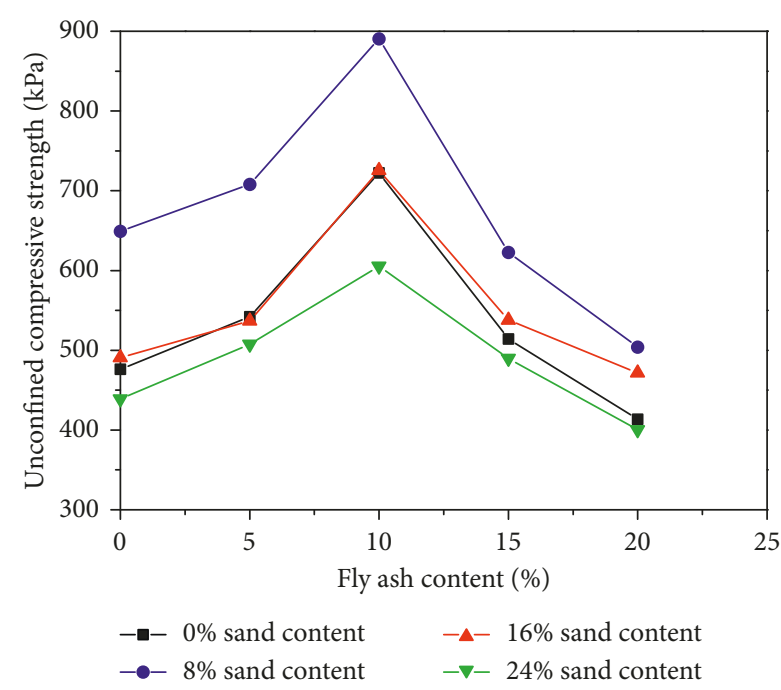

(b)

FIGURE 9: Effect of different additives on unconfined compressive strength of soil specimens. (a) Without basalt fiber. (b) With $0.4 \%$ basalt fiber.

The calculation results of the growth rate are listed in Tables 3 and 4. It is found in Table 3 that the growth rate of unconfined compressive strength of stabilized soil samples increases with increasing of fly ash content and sand content. When the fly ash content is $10 \%$ and sand content is $8 \%$, the growth rate is peaked at $127.71 \%$ for stabilized soil with $0 \%$ basalt fiber. Moreover, it is observed that the growth rate of unconfined compressive strength of stabilized soil specimens increases notably with the addition of $0.4 \%$ basalt fiber. The maximum strength growth rate of soil specimens in Figure 9(b) reaches $165.76 \%$, which shows an increase of $29.79 \%$ compared with the maximum strength growth rate in Figure 9(a). Accordingly, the role of fiber in strength improvement of stabilized soil is not negligible.

3.4.3. Complementary Effect. To verify whether there is a complementary effect among various additives on enhancing the strength of stabilized soil. The definition of $\beta_{i}$ and $\beta_{j}$ are the ratio of strength growth coefficient for the soil specimens stabilized with one additive (inclusive of fly ash, sand, or basalt fiber) compared with the untreated soil specimens. The definition of $\beta_{i j}$ is the ratio of strength growth coefficient for the soil specimens stabilized with mixtures of two additives compared with untreated soil specimens. The equations are as follows:

$$
\begin{aligned}
& \beta_{i}=\frac{\sigma_{i}}{\sigma_{0}}, \\
& \beta_{j}=\frac{\sigma_{j}}{\sigma_{0}}, \\
& \beta_{i j}=\frac{\sigma_{i j}}{\sigma_{0}},
\end{aligned}
$$

where $\sigma_{0}$ denotes the unconfined compressive strength of untreated expansive soil samples; $\sigma_{i}$ and $\sigma_{j}$ are the
TABLE 3: Growth rate of unconfined compressive strength of stabilized soil with $0 \%$ basalt fiber.

\begin{tabular}{lccccc}
\hline \multirow{2}{*}{ Sand content (\%) } & \multicolumn{5}{c}{ Fly ash content (\%) } \\
& 0 & 5 & 10 & 15 & 20 \\
\hline 0 & 0 & 31.97 & 86.30 & 38.36 & -2.71 \\
8 & 61.13 & 96.08 & 127.71 & 66.31 & 27.46 \\
16 & 31.89 & 41.83 & 92.64 & 36.95 & 7.83 \\
24 & -9.20 & 22.59 & 57.84 & 23.73 & -8.28 \\
\hline
\end{tabular}

TABLE 4: Growth rate of unconfined compressive strength of stabilized soil with $0.4 \%$ basalt fiber.

\begin{tabular}{lccccc}
\hline \multirow{2}{*}{ Sand content (\%) } & \multicolumn{5}{c}{ Fly ash content (\%) } \\
& 0 & 5 & 10 & 15 & 20 \\
\hline 0 & 42.11 & 61.76 & 115.60 & 53.45 & 23.38 \\
8 & 32.58 & 111.31 & 165.76 & 85.81 & 50.46 \\
16 & 46.41 & 60.23 & 116.54 & 60.52 & 40.77 \\
24 & 31.01 & 51.43 & 80.69 & 46.13 & 19.41 \\
\hline
\end{tabular}

unconfined compressive strength of the soil samples stabilized with one additive, i.e., fly ash or sand or basalt fiber; and $\sigma_{i j}$ is the unconfined compressive strength of the soil samples stabilized with two additives.

The complementary coefficient $\theta$ is defined by the following equation:

$$
\theta=\frac{\beta_{i j}^{2}}{\beta_{i} \cdot \beta_{j}} .
$$

When $\theta \geq 1$, it is positive complementary effect for the strength enhancement of stabilized soil; when $\theta<1$, it is negative complementary effect for the strength enhancement of stabilized soil. The calculation results of the complementary coefficient are listed in Tables 5-7. It is concluded that most of the stabilized soil specimens have 
a characteristic of positive complementary effect. The above results demonstrate that the soil specimens stabilized with mixtures of two additives have a more obvious strength enhancement than that stabilized with only one additive. Besides, the results indicated that there is a good combination between various additives used in this study.

\section{Microstructural Analysis}

To better understand the observed macroscopic behaviors of stabilized soil such as plasticity index, compaction strength, and unconfined compressive strength, the soil microstructure observation should be performed. On the one hand, the microstructure of soil reveals the internal structures of soil and the formation of hydration products and aggregations inside soil. On the other hand, it is an important factor to determine the physical, mechanical, and other engineering properties of soil [26].

4.1. Effect of Fly Ash Content. The SEM images of expansive soil samples at different fly ash contents after 28 days of curing period are given in Figure 10. It is presented that the microstructure of virgin expansive soil samples and fly ashstabilized soil samples is completely different. At low magnification, Figures 10(a), 10(b), and 10(c) suggest that the pores inside soil samples are gradually filled with the hydration products with increasing of fly ash dosage. For the soil specimens stabilized with $0 \%$ fly ash, it can be observed that the structure of soil aggregates is composed of soil particles and inter-aggregates pores. The effect of fly ash on expansive soil samples is shown in Figures 10(b) and 10(c), and a granular structure with hydration products is clearly observed. This implies that the addition of fly ash promotes the occurrence of pozzolanic reaction and helps in binding the unbonded soil particles.

At 1500 times magnification, it is found that hydration products generated in the inter-aggregates pores, as shown in Figures 10(e) and 10(f). There is a cation exchange reaction (substitution of the $\mathrm{Na}^{+}$or $\mathrm{K}^{+}$ions by the $\mathrm{Al}^{3+}$ or $\mathrm{Ca}^{2+}$ ions) between fly ash and soil particles with the increase of fly ash content. The results of cation exchange reaction presented a trend of flocculation of particles [21], as shown in Figures 10(e) and 10(f). The gels of calcium silicate hydrates are the products of $\mathrm{SiO}_{2}$ in fly ash reacted with $\mathrm{Ca}^{2+}$ ions and $\mathrm{OH}^{-}$ions (formed by ionization of $\mathrm{Ca}$ $\left.(\mathrm{OH})_{2}\right)$ [9], which can effectively increase the strength and integrality of stabilized soil. However, the fly ash cannot react with soil particles completely if the amount of fly ash is excessive. It is clear as shown in Figure 10(f) that when the addition of fly ash is in a proportion of $20 \%$, the spherical fly ash particles are still present among soil particles without reaction. Since fly ash is a nonstick material, the unreacted fly ash particle remained inside soil samples reduces the interparticle connection and the bonding force between soil particles. The unconfined compressive strength of stabilized soil with excessive fly ash (such as $20 \%$ fly ash dosage) decreases accordingly in previous tests. At 5000 times magnification, it is clear
TABLE 5: Complementary coefficient of soil specimens stabilized with fly ash and sand.

\begin{tabular}{lccccc}
\hline \multirow{2}{*}{ Sand content (\%) } & \multicolumn{5}{c}{ Fly ash content (\%) } \\
& 0 & 5 & 10 & 15 & 20 \\
\hline 0 & 1 & 1.32 & 1.86 & 1.38 & 0.97 \\
8 & 1.61 & 1.81 & 1.73 & 1.24 & 1.04 \\
16 & 1.32 & 1.16 & 1.51 & 1.03 & 0.91 \\
24 & 0.91 & 1.25 & 1.47 & 1.22 & 0.95 \\
\hline
\end{tabular}

TABLE 6: Complementary coefficient of soil specimens stabilized with fly ash and basalt fiber.

\begin{tabular}{lccccc}
\hline \multirow{2}{*}{ Basalt fiber content (\%) } & \multicolumn{5}{c}{ Fly ash content (\%) } \\
& 0 & 5 & 10 & 15 & 20 \\
\hline 0 & 1 & 1.32 & 1.86 & 1.38 & 0.97 \\
0.4 & 1.42 & 1.40 & 1.76 & 1.20 & 1.10 \\
\hline
\end{tabular}

TABle 7: Complementary coefficient of soil specimens stabilized with sand and basalt fiber.

\begin{tabular}{lcccc}
\hline \multirow{2}{*}{ Basalt fiber content (\%) } & \multicolumn{4}{c}{ Sand content (\%) } \\
& 0 & 8 & 16 & 24 \\
\hline 0 & 1 & 1.61 & 1.32 & 0.91 \\
0.4 & 1.42 & 1.64 & 1.14 & 1.33 \\
\hline
\end{tabular}

that the calcium silicate hydrates (C-S-H) and calcium sulfoaluminate hydrates (AFt) were filled in the interaggregates pores as shown in Figures 10(h) and 10(i). Yet, there are many inter-aggregates pores as shown in Figure $10(\mathrm{~g})$. Moreover, the microstructure observed in the fly ash-stabilized soil specimens by SEM can be considered as compact, which indicates an intact structure. The micrograph of soil samples treated with fly ash shows a dense fabric with cementitious products or aggregations. The formation of aggregations is responsible for the mitigation of the swelling potential of expansive soils, so the plasticity index presents a decreasing trend in Figure 6.

4.2. Effect of Sand Content. Figure 11 presents the SEM images of expansive soil samples stabilized with $10 \%$ fly ash at different sand contents after 28 days of curing period. It is directly shown that all the stabilized soil samples have the same fly ash content of $10 \%$ and the interparticle pores inside soil samples gradually decrease with the increase of sand content. With the addition of sand, the pores between soil particles are filled with sand and the inter-aggregates pores are also filled with sand simultaneously. Thus, the integrality and compactness of stabilized soil improve remarkably in the presence of sand.

4.3. Effect of Fiber Reinforcement. Figure 12 gives the SEM images of the effect of fiber reinforcement on microstructure of stabilized expansive soil. Figure 12(a) presents a SEM image of the untreated soil specimen. It presents that the internal structure of expansive soil is a turbulent 


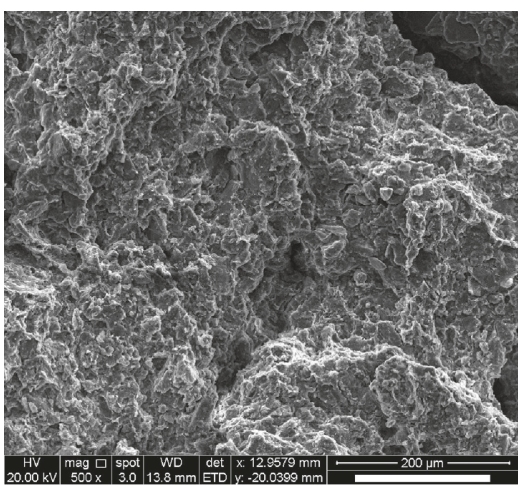

(a)

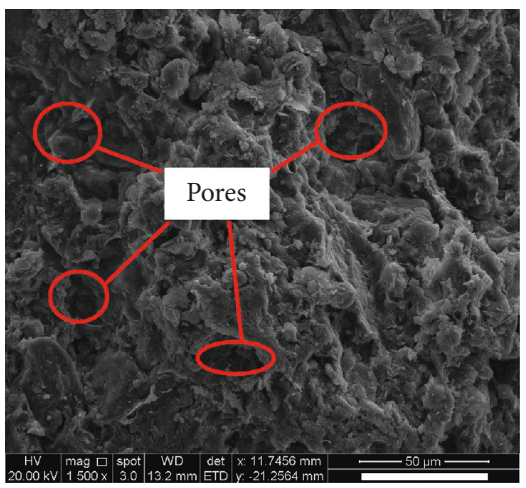

(d)

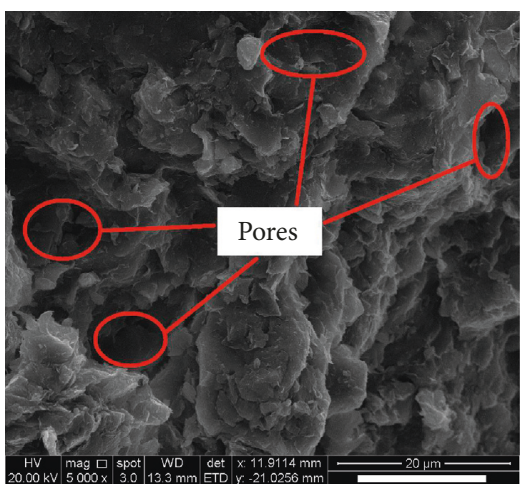

(g)

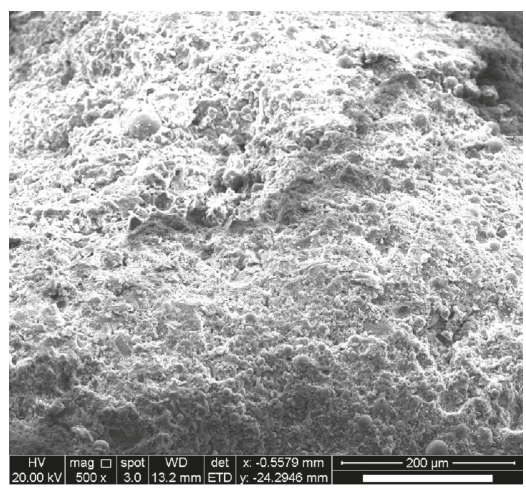

(b)

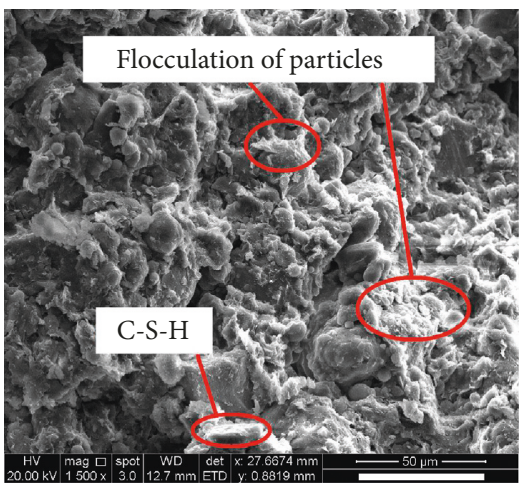

(e)

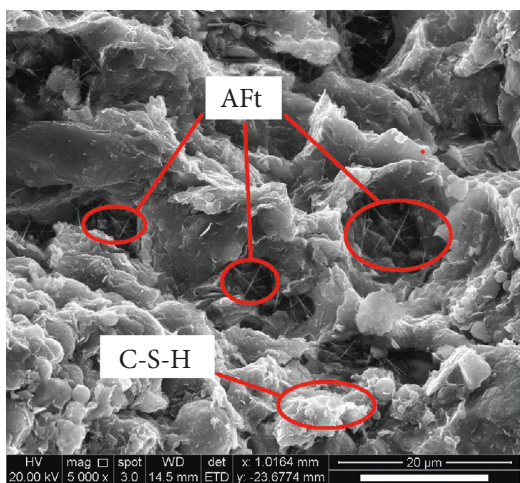

(h)

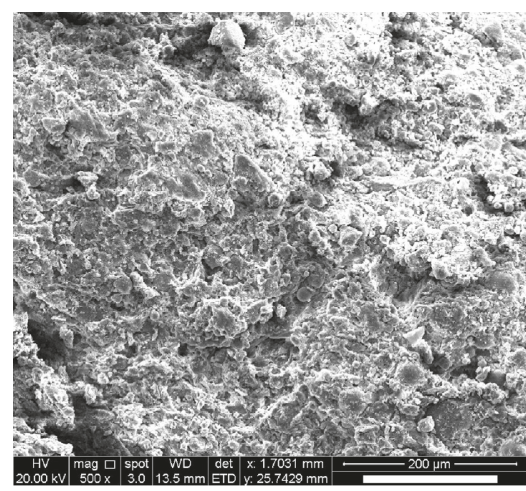

(c)

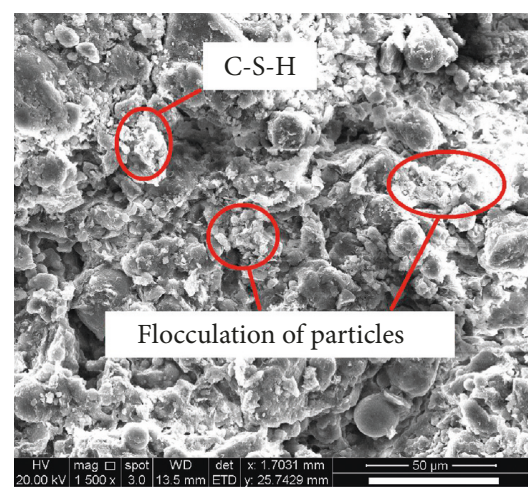

(f)

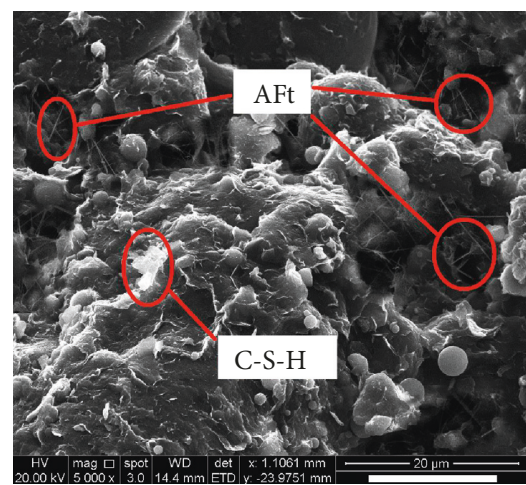

(i)

Figure 10: Microstructure of stabilized expansive soil under different fly ash contents. (a) $0 \%$ fly ash ( $\times 500)$. (b) $10 \%$ fly ash ( $\times 500)$. (c) $20 \%$

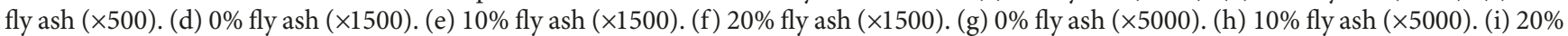
fly ash $(\times 5000)$.

structure, and the result complies with the experimental result of Mao and Xia [26]. Figure 12(b) shows the shape and location of basalt fibers appeared inside stabilized soil specimens. It can be easily seen that the basalt fibers are tightly wrapped by the ambient clay particles. Due to the gripping interactions between fibers and soil particles, they jointly bear the external loading $[27,28]$. When stabilized soil is subjected to external loading, the interfacial force between clay particles and fibers increases gradually to resist external loading [29]. As a result, the strength of stabilized soil evidently increases with the addition of basalt fiber, and this point has been confirmed in Section 3.4.2 from a macroscopic perspective. At higher magnification,
Figures 12(c) and 12(d) show this gripping effect between fibers and soil particles more clearly.

4.4. Effect of Sand Content on Fiber Reinforcement. The SEM images of the effect of sand on microstructure of expansive soil stabilized with $0.4 \%$ basalt fiber are given in Figure 13 . With the certain percentage of fly ash (10\%), the superficial roughness of fiber increases with the increase of sand content. It is clearly observed that the basalt fiber presented in Figures 13(b) and 13(c) has a rugged surface with the addition of sand to stabilized soil. Figures 13(e) and 13(f) show more clearly. The surface of the basalt fiber has 


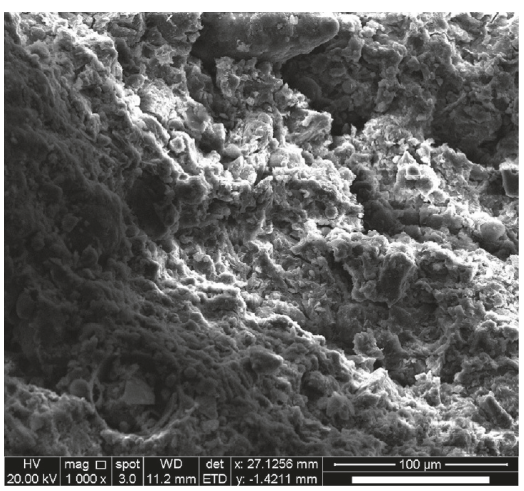

(a)

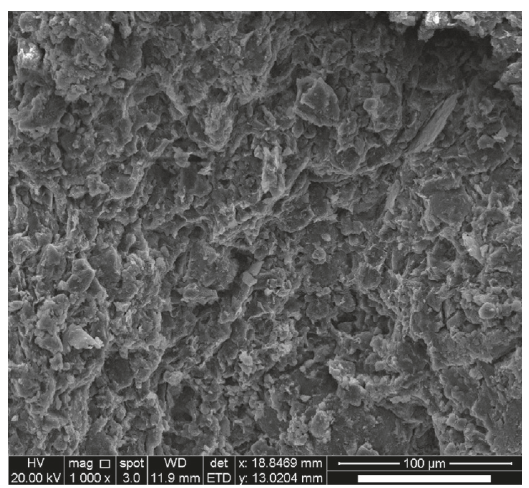

(b)

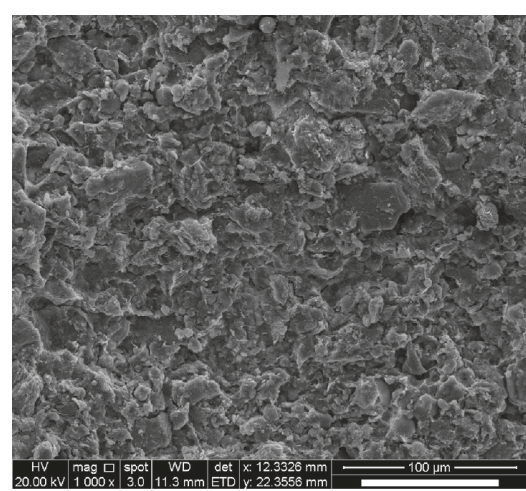

(c)

FIgURe 11: Microstructure of expansive soil stabilized with $10 \%$ fly ash at different sand contents. (a) $0 \%$ sand and $10 \%$ fly ash ( $\times 1000$ ). (b) $8 \%$ sand and $10 \%$ fly ash $(\times 1000)$. (c) $24 \%$ sand and $10 \%$ fly ash $(\times 1000)$.

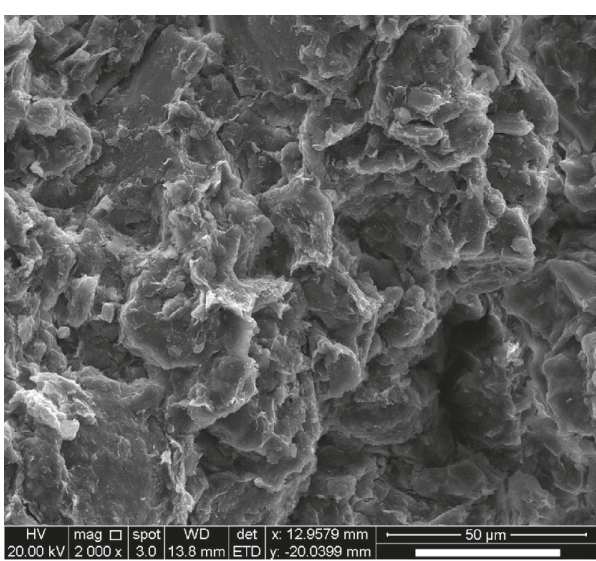

(a)

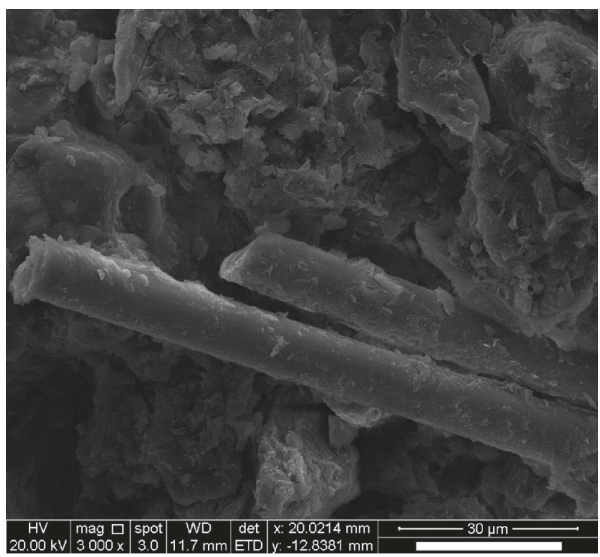

(c)

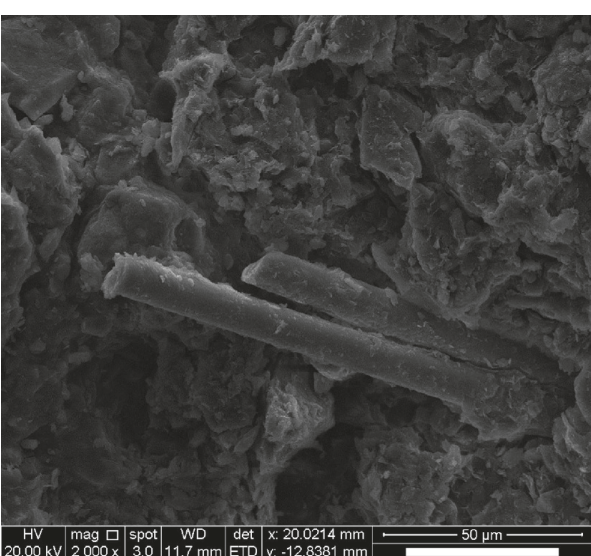

(b)

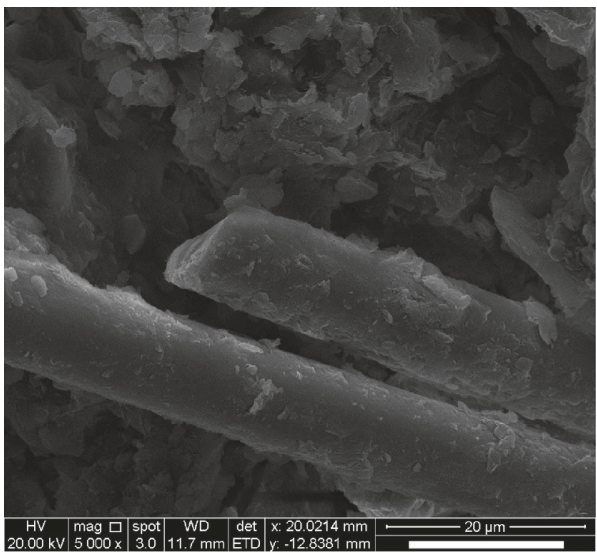

(d)

FigURE 12: Effect of fiber reinforcement on microstructure of stabilized expansive soil. (a) Without basalt fiber ( $\times 2000)$. (b) With $0.4 \%$ basalt fiber $(\times 2000)$. (c) With $0.4 \%$ basalt fiber $(\times 3000)$. (d) With $0.4 \%$ basalt fiber $(\times 5000)$.

mechanically damaged because of the impact between sand grains and fibers during mixing or compressing [25]. The hardness of the sand is higher than that of the basalt fiber. Under the action of the external loading, the fiber surface undergoes extrusion deformation and becomes rugged. Undoubtedly, the friction force between fibers and soil particles increases with the increase of the surface area between fibers and soil particles. As a result, the presence of sand contributes to the connection between soil particles and the enhancement of interfacial force between fibers and soil particles. From a macro point of view, the strength of stabilized soil increases significantly and the fiber-stabilized soil presents a positive complementary effect with the addition of sand. 


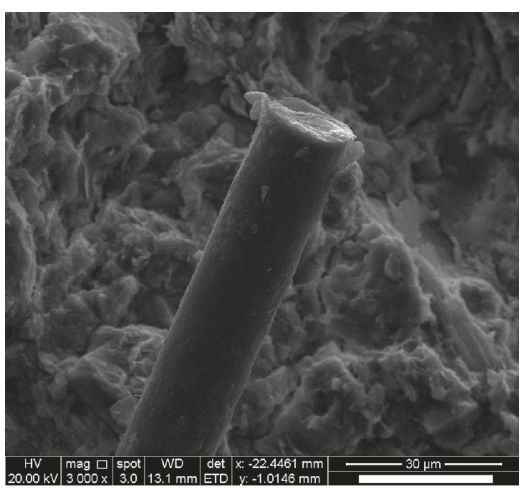

(a)

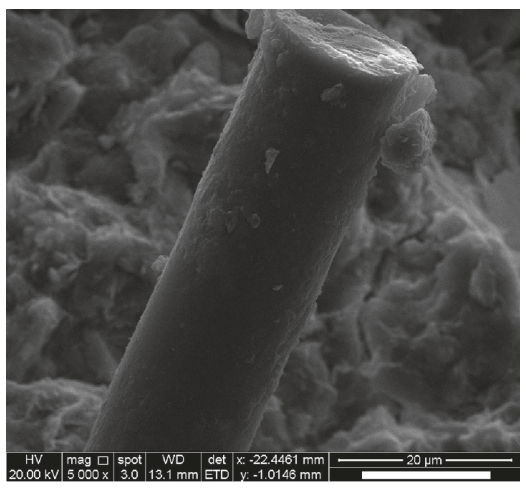

(d)

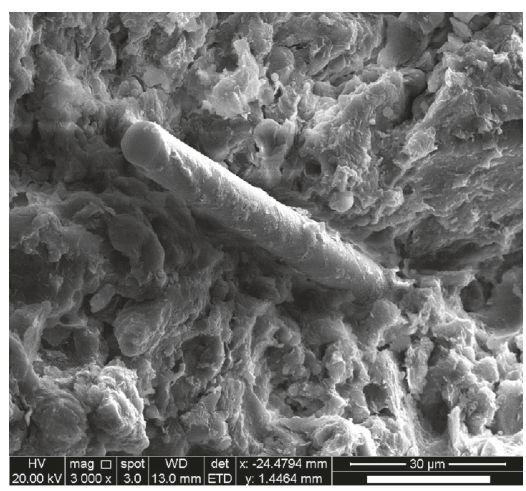

(b)

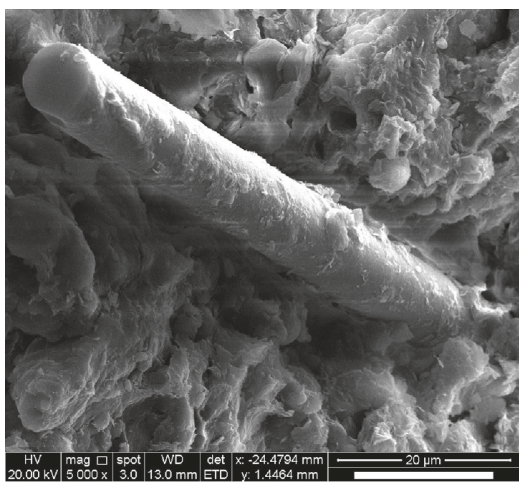

(e)

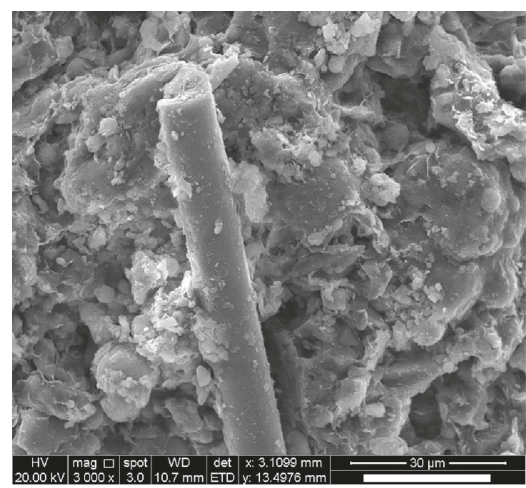

(c)

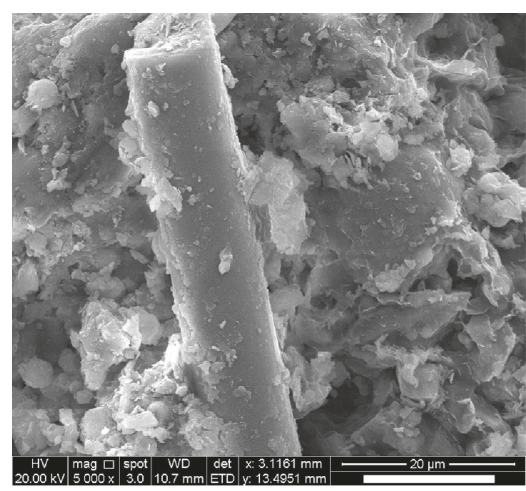

(f)

Figure 13: Effect of sand content on microstructure of fiber-stabilized soil. (a) $0 \%$ sand and $10 \%$ fly ash ( $\times 3000$ ). (b) $8 \%$ sand and $10 \%$ fly ash (×3000). (c) $24 \%$ sand and $10 \%$ fly ash (×3000). (d) $0 \%$ sand and $10 \%$ fly ash $(\times 5000)$. (e) $8 \%$ sand and $10 \%$ fly ash $(\times 5000)$. (f) $24 \%$ sand and $10 \%$ fly ash $(\times 5000)$.

\section{Conclusions}

This paper analyzes the physical-mechanical properties and microstructures of stabilized expansive soil by performing a series of laboratory experiments. Then, the effect of various additives on physical performances, unconfined compressive strength, and microstructure is highlighted in this study. Conclusions are drawn as follows:

(1) The physical properties of stabilized soil are different with the original expansive soil. With the addition of fly ash, specific gravity of stabilized soil goes on decreasing as the percentage of fly ash increases from $0 \%$ to $20 \%$. In contrast, specific gravity of stabilized soil is increasing with the increase of sand content. The optimum moisture content of stabilized soil shows an increasing trend with the addition of fly ash, and the optimum moisture content shows a reducing trend with the increase of sand content. Yet, the maximum dry density of stabilized soil decreases with the increase of fly ash content and increases with the increase of sand content. The plastic limit and liquid limit of original expansive soil are $22 \%$ and $42.8 \%$, respectively. With the addition of fly ash or sand, there is reduction in the liquid limit value, whereas the plastic limit value presents an increasing trend. The plasticity index of stabilized soil decreases with the increase of fly ash or sand content.

(2) Unconfined compression test is performed to clarify the strength improvement of stabilized soil with various additives. It is found that the failure mode of stabilized soil with fiber can be transformed from brittle failure to plastic failure. The maximum unconfined compressive strength and the best growth rate of strength are acquired for mixt treatments with $10 \%$ fly ash and $8 \%$ sand contents. All the performances of stabilized soil have further upgraded with the addition of $0.4 \%$ basalt fiber. Therefore, it is concluded that the addition of fly ash, sand, and basalt fiber mixture can be considered as an efficient stabilization method for strength enhancement of expansive soil. As the analysis of complementary effect suggests, most of the mixt treatments applied in this study have produced good results concerned with the enhancement of strength of expansive soil. Moreover, the analysis of complementary effect indicates that there is a good combination between different stabilizers used in this study.

(3) Owing to the generation of hydration products of fly ash, the connection among clay particles has been enhanced. At 5000 times magnification, it is easily found that the calcium silicate hydrates $(\mathrm{C}-\mathrm{S}-\mathrm{H})$ and 
calcium sulfoaluminate hydrates (AFt) are filled in the inter-aggregates pores in SEM images. Besides, the flocculation of dispersed clay particles occurs under the ionization of divalent and trivalent cations with the addition of fly ash. For the content of fly ash is $20 \%$, the spherical fly ash particles still exist among soil particles without reaction in SEM images. The unreacted fly ash particles remained in the soil particles will reduce the interparticle connection. The suitable proportion of sand has a good filling effect on inter-aggregates pores; hence, the integrality and compactness of stabilized soil have increased. The gripping effect between fibers and soil particles notably increases the strength of stabilized soil. Furthermore, the surface of the fiber becomes rugged due to the impact between sand grains and fibers in the process of mixing or compressing, and the friction force between fibers and soil particles increases directly. As a result, the effect of sand on reinforced soil with $0.4 \%$ basalt fiber can improve the connection between soil particles and the interfacial force between fibers and soil particles, which suggests that the use of mixt additives shows a positive effect on the stabilization of expansive soil.

\section{Data Availability}

The data used to support the findings of this study are available from the corresponding author upon request.

\section{Conflicts of Interest}

The authors declare that they have no conflicts of interest regarding the publication of this paper.

\section{Acknowledgments}

The authors sincerely thank the Engineering Research Center of Underground Mine Construction, Ministry of Education, and the Anhui University of Science and Technology for providing the experiment conditions. And the authors would like to acknowledge the College of Civil Engineering and Architecture, Zhejiang University, for their support during completion of SEM tests.

\section{References}

[1] A. Seco, F. Ramírez, L. Miqueleiz, and B. García, "Stabilization of expansive soils for use in construction," Applied Clay Science, vol. 51, no. 3, pp. 348-352, 2011.

[2] S. B. Ikizler, M. Vekli, E. Dogan, M. Aytekin, and F. Kocabas, "Prediction of swelling pressures of expansive soils using soft computing methods," Neural Computing and Applications, vol. 24, no. 2, pp. 473-485, 2014.

[3] R. N. Yong and V. R. Ouhadi, "Experimental study on instability of bases on natural and lime/cement-stabilized clayey soils," Applied Clay Science, vol. 35, no. 3-4, pp. 238-249, 2007.

[4] M. Khemissa and A. Mahamedi, "Cement and lime mixture stabilization of an expansive overconsolidated clay," Applied Clay Science, vol. 95, pp. 104-110, 2014.
[5] M. Al-Mukhtar, A. Lasledj, and J. F. Alcover, "Behaviour and mineralogy changes in lime-treated expansive soil at $20^{\circ} \mathrm{C}$," Applied Clay Science, vol. 50, no. 2, pp. 191-198, 2010.

[6] A. R. Estabragh, M. R. S. Pereshkafti, B. Parsaei, and A. A. Javadi, "Stabilised expansive soil behaviour during wetting and drying," International Journal of Pavement Engineering, vol. 14, no. 4, pp. 418-427, 2013.

[7] R. S. Sharma, B. R. Phanikumar, and B. V. Rao, "Engineering behavior of a remolded expansive clay blended with lime, calcium chloride, and rice-husk ash," Journal of Materials in Civil Engineering, vol. 20, no. 8, pp. 509-515, 2008.

[8] T. Thyagaraj, S. M. Rao, P. S. Suresh, and U. Salini, "Laboratory studies on stabilization of an expansive soil by lime precipitation technique," Journal of Materials in Civil Engineering, vol. 24, no. 8, pp. 1067-1075, 2012.

[9] B. R. Phanikumar and R. S. Sharma, "Volume change behavior of fly ash-stabilized clays," Journal of Materials in Civil Engineering, vol. 19, no. 1, pp. 67-74, 2007.

[10] A. S. Rao and M. R. Rao, "Swell-shrink behaviour of expansive soils under stabilized fly ash cushions," in Proceedings of the 12th International Conference on International Association for Computer Methods and Advances in Geomechanics, pp. 561-564, Goa, India, December 2008.

[11] M. G. Feng, S. X. Chen, S. Yu, and J. Ma, "Laboratory study on water stability of fly ash-treated expansive soil," Rock and Soil Mechanics, vol. 28, no. 9, pp. 1889-1893, 2007, in Chinese.

[12] X. Kang, L. Ge, G. C. Kang, and C. Mathews, "Laboratory investigation of the strength, stiffness, and thermal conductivity of fly ash and lime kiln dust stabilised clay subgrade materials," Road Materials and Pavement Design, vol. 16, no. 4, pp. 928-945, 2015.

[13] S. K. Mohanty, P. K. Pradhan, and C. R. Mohanty, "Consolidation and drainage characteristics of expansive soil stabilized with fly ash and dolochar," Geotechnical and Geological Engineering, vol. 34, no. 5, pp. 1435-1451, 2016.

[14] P. K. Kolay and K. C. Ramesh, "Reduction of expansive index, swelling and compression behavior of kaolinite and bentonite clay with sand and class C fly ash," Geotechnical and Geological Engineering, vol. 34, no. 1, pp. 87-101, 2016.

[15] S. Y. Lei and W. T. Ding, "Experimental investigation on restraining the swell of expansive soil with fibre-reinforcement," Chinese Journal of Geotechnical Engineering, vol. 27, no. 4, pp. 482-485, 2005, in Chinese.

[16] Y. S. Deng, P. Wu, M. H. Zhao, and B. Z. Duan, "Strength of expansive soil reinforced by polypropylene fiber under optimal water content," Rock and Soil Mechanics, vol. 38, no. 2, pp. 349-360, 2017, in Chinese.

[17] J. Prabakar and R. S. Sridhar, "Effect of random inclusion of sisal fibre on strength behaviour of soil," Construction and Building Materials, vol. 16, no. 2, pp. 123-131, 2002.

[18] T. Yetimoglu and O. Salbas, "A study on shear strength of sands reinforced with randomly distributed discrete fibers," Geotextiles and Geomembranes, vol. 21, no. 2, pp. 103-110, 2003.

[19] X. Qin, A. Q. Shen, Y. C. Guo, Z. N. Li, and Z. H. Lv, "Characterization of asphalt mastics reinforced with basalt fibers," Construction and Building Materials, vol. 159, pp. 508-516, 2018.

[20] L. Gao, G. H. Hu, N. Xu, J. Y. Fu, C. Xiang, and C. Yang, "Experimental study on unconfined compressive strength of basalt fiber reinforced clay soil," Advances in Materials Science and Engineering, vol. 2015, Article ID 561293, 8 pages, 2015. 
[21] Y. L. Chen, "Microstructure of expansive soil from Yunnan Province," Chinese Journal of Geotechnical Engineering, vol. 35, no. S1, pp. 334-339, 2013, in Chinese.

[22] S. Horpibulsuk, R. Rachan, A. Chinkulkijniwat, and Y. Raksachon, "Analysis of strength development in cementstabilized silty clay from microstructural considerations," Construction and Building Materials, vol. 24, no. 10, pp. 2011-2021, 2010.

[23] American Society for Testing and Materials (ASTM), ASTM C 618-03, Standard Specification for Coal Fly Ash and Raw or Calcined Natural Pozzolan for Use as a Mineral Admixture in Concrete, Annual Book of ASTM Standards, Philadelphia, USA, 2003.

[24] Ministry of Construction of the People's Republic of China, GB/T 50123-1999 Standard for Soil Test Method, China Planning Press, Beijing, China, 1999, in Chinese.

[25] C. S. Tang, B. Shi, W. Gao, Y. Cai, and J. Liu, "Study on effects of sand content on strength of polypropylene fiber reinforced clay soil," Chinese Journal of Rock Mechanics and Engineering, vol. 26, no. S1, pp. 2968-2973, 2007, in Chinese.

[26] T. E. Mao and L. Xia, "Experimental research on microstructure of expansive soil in north of Hubei Province," Journal of Huazhong University of Science and Technology (Urban Science Edition), vol. 27, no. 2, pp. 48-52, 2010, in Chinese.

[27] C. S. Tang, B. Shi, and K. Gu, "Microstructural study on interfacial interaction between fiber reinforcement and soil," Journal of Engineering Geology, vol. 19, no. 4, pp. 610-614, 2011, in Chinese.

[28] C. S. Tang, B. Shi, and L. Z. Zhao, "Interfacial shear strength of fiber reinforced soil," Geotextiles and Geomembranes, vol. 28, no. 1, pp. 54-62, 2010.

[29] N. Cristelo, V. M. C. F. Cunha, M. Dias, A. T. Gomes, T. Miranda, and N. Araújo, "Influence of discrete fibre reinforcement on the uniaxial compression response and seismic wave velocity of a cement-stabilised sandy-clay," Geotextiles and Geomembranes, vol. 43, no. 1, pp. 1-13, 2015. 


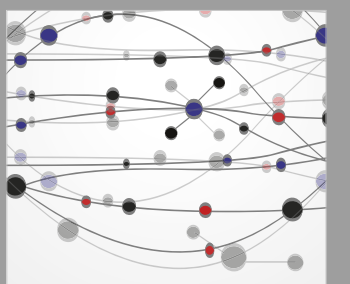

The Scientific World Journal
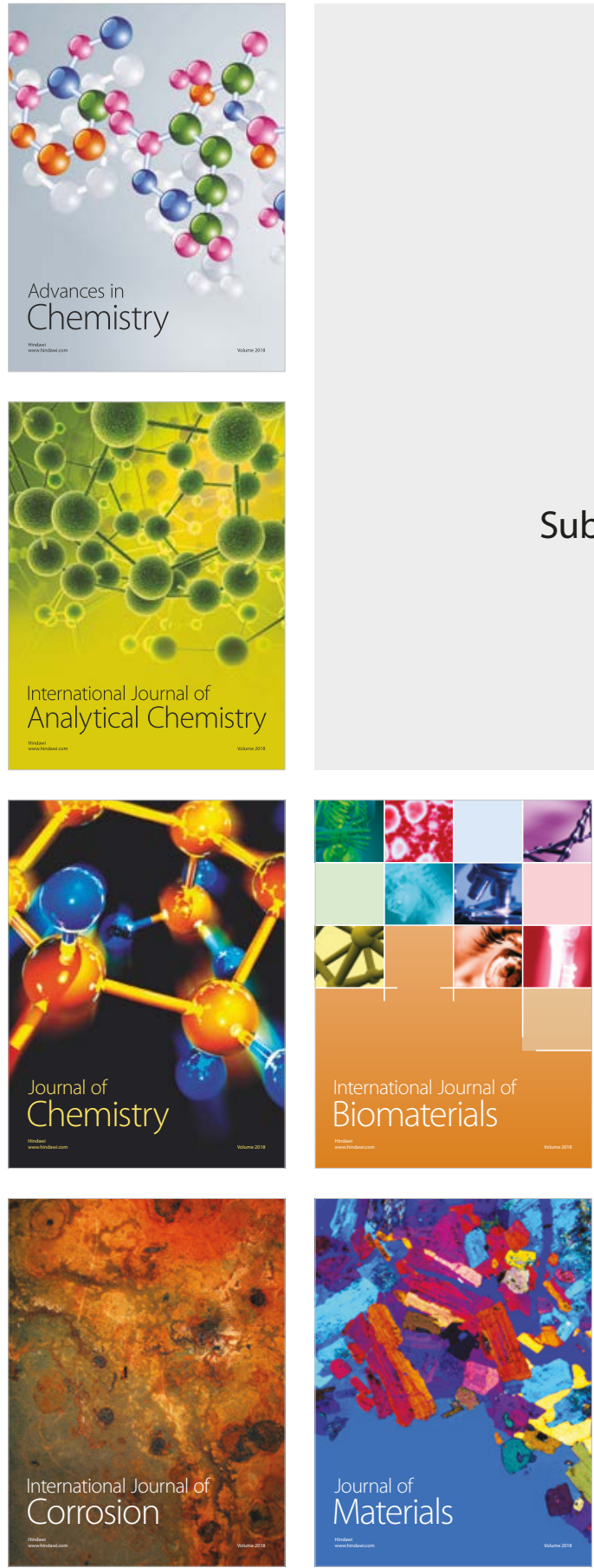

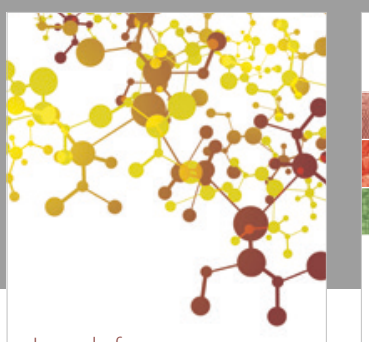

Journal of

Applied Chemistry
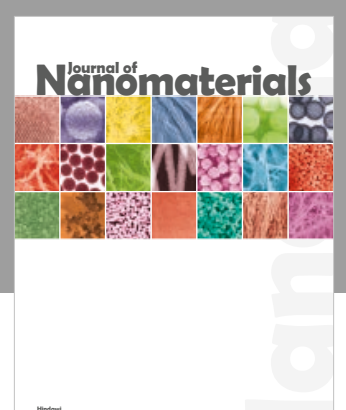

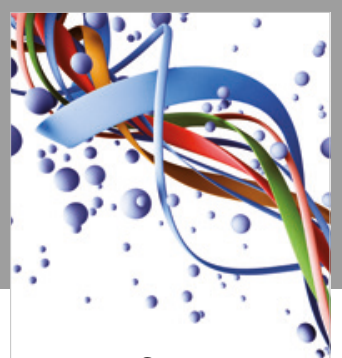

Scientifica

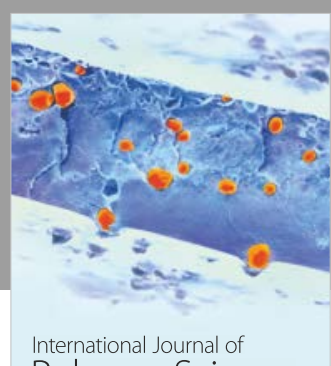

Polymer Science

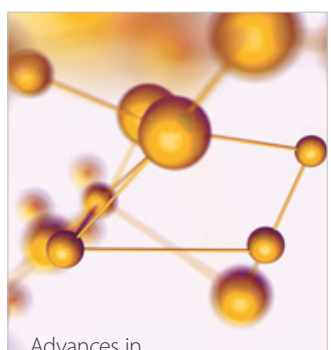

Physical Chemistry
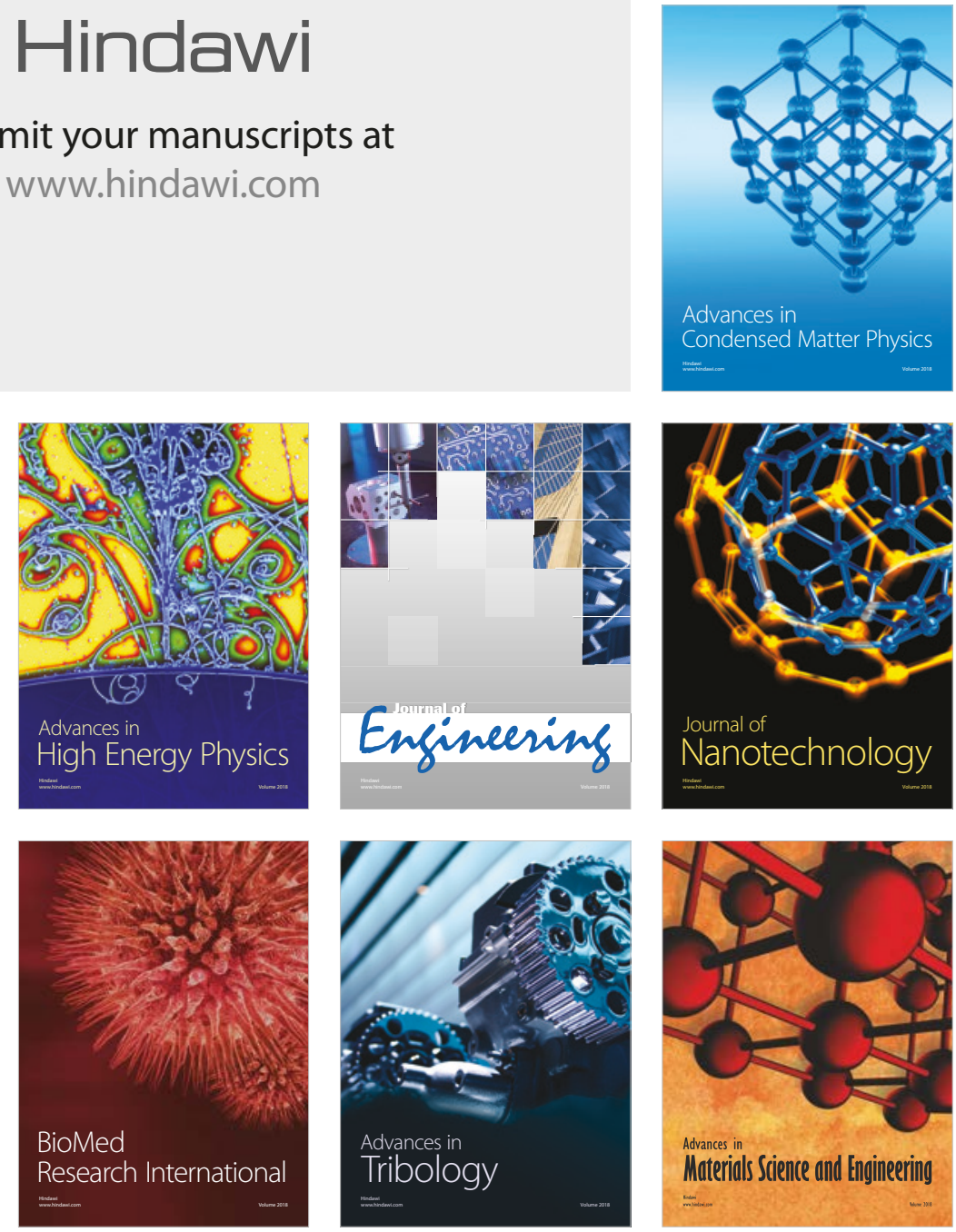